\title{
O significado do conceito "corrupção" na semântica política da crise brasileira (2013-2016)
}

Rodrigo Perez Oliveira*

Resumo: Nos últimos anos, o sistema político brasileiro foi desestabilizado por uma crise que extravasou os limites das instituições da República e chegou às ruas. Essa experiência de crise pode ser examinada de diversas maneiras, o que vem sendo feito pela bibliografia especializada. Aqui, neste artigo, analiso um momento específico da evolução da crise: o período compreendido entre as “jornadas de junho de 2013" e a destituição da Presidenta Dilma Rousseff, com o objetivo de compreender a dimensão semântica de crise, através das narrativas que se materializaram em práticas políticas e levaram os setores da sociedade brasileira diretamente envolvidos nos conflitos em tela a representaram a realidade em uma determinada perspectiva. Minha hipótese é que entre 2013 e 2016, a semântica da crise brasileira esteve baseada na hipertrofia de um sentido específico do conceito "corrupção" e, por consequência lógica, numa forma de tratar o problema da "ética na política" que apontam para tópicas pertencentes ao repertório do liberalismo conservador que já circulavam na cena política brasileira desde a década de 1990 .

Palavras-chave: Crise Brasileira. Liberalismo Conservador. Corrupção. Semântica Política. Práticas Políticas.

\footnotetext{
"Professor de Teoria da História na Universidade Federal da Bahia (UFBA). Doutorado em História pela Universidade Federal do Rio de Janeiro (UFRJ). E-mail: rodrigoperez@ufba.br, https://orcid.org/0000-0002-9584-944X
} 
O significado do conceito "corrupção" na semântica política...

\section{Introdução}

Eu e meus amigos estamos cansados de tanta história de corrupção e impunidade. Sabe quanto desaparece dos cofres públicos todo ano no Brasil? 200 bilhões de reais. Isso é dinheiro nosso, da sociedade, do povo, que precisa de mais saúde, educação e segurança. Com essa dinheirada, vamos poder comer melhor, nos vestir melhor. O aumento da passagem de ônibus foi só a gota d'água que fez transbordar o copo. Um copo cheio de insatisfações. Está todo mundo indignado com tanta afronta (REVISTA VEJA, 2013, p. 17).

É certo que, de 2013 até o momento em que escrevo este artigo, o Brasil vive a mesma experiência de crise institucional. No entanto, se formos examinar com mais cuidado a cronologia dos acontecimentos, seremos capazes de identificar momentos específicos que configuraram a evolução do cenário de crise, provocando realinhamentos distintos dentro da classe política e impactando de diferentes maneiras a sociedade civil. Sendo assim, acredito que o dia 3 de julho de 2013 representa uma data chave para a compreensão dessa cronologia, pois foi nesse momento que a Revista Veja publicou a sua edição de número 2328 , onde foi representada pela primeira vez a narrativa que se tornaria o fundamento semântico da crise brasileira. $\mathrm{O}$ meu objetivo neste texto é examinar essa narrativa, reconstruindo o seu surgimento, a sua historicidade e analisando os seus desdobramentos na esfera das práticas políticas.

A edição 2328 da Revista Veja marcou a conclusão de uma guinada na cobertura feita pela grande mídia dos protestos populares que aprendemos a chamar de “jornadas de junho de 2013". Nessa edição foi publicada, na seção Páginas Amarelas, uma entrevista com o "jovem” Maycon de Freitas, "[...] a voz que emergiu das ruas e reuniu milhares de pessoas na luta contra a corrupção", para usar as palavras da própria reportagem. A entrevista precisa ser situada num movimento de reorientação semântica que teve início no Jornal Nacional, da Rede Globo, em meados de junho. Em um curto espaço de duas semanas, os manifestantes deixaram de ser 
representados como vândalos e passaram ser tratados como "brasileiros de bem" indignados com a corrupção praticada pela classe política. A "corrupção", então, foi cada vez mais se tornando a ideia mestra e o discurso motriz da crise institucional, tendo grande apelo junto à opinião pública, que passou a ser diariamente sensibilizada por uma narrativa de espetacularização de denúncias, desenvolvida pela imprensa hegemônica tanto nos veículos televisivos como nos impressos. Essa narrativa alimentou uma semântica política liberal conservadora, baseada na premissa de que o Estado é naturalmente corrompido e corruptor. Este argumento já foi desenvolvido pelo sociólogo Jessé Souza, especialmente nos livros "A tolice da inteligência brasileira" e "A elite do atraso", ambos encontrando grande acolhida no mercado editorial. Tomo a discussão proposta pelo autor como ponto de partida. Meu objetivo é delinear contornos mais precisos ao argumento de Jessé Souza, mostrando empiricamente como esse uso seletivo do conceito corrupção já vem sendo feito na cena política brasileira desde a década de 1990. Quero abordar aqui a ancestralidade semântica da crise brasileira contemporânea.

Como na dinâmica da crise brasileira o liberalismo conservador se tornou hegemônico, a partir de um significado específico da ideia de "corrupção"? Como essa semântica se materializou em práticas políticas? São esses os problemas sobre os quais me debruço neste artigo.

Para organizar melhor a reflexão, divido o texto em três partes: em um primeiro momento, o meu esforço é o de reconstruir os movimentos iniciais da crise, examinando suas origens, lançando luz sobre a primeira agenda das “jornadas de junho de 2013" e demonstrando como a mídia hegemônica interferiu diretamente na dinâmica dos protestos populares. Em seguida, trato da segunda fase das manifestações populares, que teve início em janeiro de 2015, logo após a reeleição de Dilma Rousseff, demonstrando o fortalecimento da semântica política liberal conservadora, caracterizada por um sentido específico do conceito "corrupção" e por um forte sentimento antiestatista. Por último, examino a ancestralidade da crise, lançando luz sobre a circulação dessas tópicas liberais conservadoras na cena política brasileira já nos 1990 . 


\section{A reconstrução do cenário de crise}

No momento em que escrevo este artigo, muitas interpretações estão disputando a representação da crise brasileira. Vários são os atores sociais envolvidos nessas disputas, indo desde aqueles que apoiaram a derrubada do governo comandado por Dilma Rousseff, passando pelos aliados da Presidenta destituída e chegando até aos seus críticos de esquerda. Para os primeiros, a crise é o resultado da indignação da sociedade civil com a corrupção, entendida como sinônimo de um assalto institucionalizado aos cofres públicos, o que teria se aprofundado nos anos em que o Brasil foi governado pelo Partido dos Trabalhadores. Já os aliados da Presidenta Dilma interpretam a crise como o resultado da manipulação midiática, que somada à conspiração levada às últimas consequências pela aliança formada por grupos políticos de oposição, pela mídia hegemônica e por setores de instituições jurídicas e policiais (como o Ministério Público e a Polícia Federal), lançou o país em uma situação de Golpe de Estado. Por sua vez, os críticos de esquerda afirmam ser a crise o resultado do esgotamento do sistema político forjado na redemocratização, que não mais seria capaz de representar os interesses da sociedade civil, o que traz a necessidade de uma ampla reforma institucional capaz de possibilitar a implantação de mecanismos que viabilizem experiências de participação política direta. Nesta perspectiva, o próprio Partido dos Trabalhadores é tratado como o porta voz de um sistema político carcomido e ultrapassado.

\section{As insurreições de junho de 2013 e o início da crise}

Acredito ser um consenso entre os observadores da cena política brasileira contemporânea que a atual crise começou no início de junho de 2013, na esteira de protestos populares organizados pelo Movimento Passe Livre, o MPL. O consenso, contudo, termina aqui, pois as "Jornadas de junho" são objeto de acaloradas disputas interpretativas. Jessé Souza, por exemplo, traça uma linha de continuidade entre os eventos de junho de 2013 e a destituição da Presidenta Dilma Rousseff, que aconteceu em meados de 2016. Para o autor, junho de 2013 foi um contra-ataque do capital financeiro 
especulativo, que havia sido diretamente confrontado por Dilma Rousseff entre 2011 e 2012, naquilo que já na época ficou conhecido como a batalha dos spreads. Nas palavras de Jessé de Souza:

Existe uma linha clara de continuidade entre as glorificadas e midiaticamente manipuladas manifestações de junho de 2013, as assim chamadas “jornadas de junho", e o golpe de abril de 2016. Nesse intervalo de quase três anos, o ataque ao governo foi realizado sem tréguas até a vitória final no processo de impeachment. As manifestações de junho de 2013 marcam o ponto de virada da hegemonia ideológica então dominante e das altas taxas de aprovação aos presidentes dos governos petistas. $\mathrm{Na}$ verdade, representam o início do cerco ideológico até hoje mal compreendido pela enorme maioria da população. A grande questão é como protestos localizados com foco em políticas municipais foram manipulados de tal modo a se "federalizarem" e atingirem a popularidade da Presidenta Dilma, que àquela altura gozava dos mais altos índices de aprovação no seu governo (SOUZA, 2016, p. 86).

O também sociólogo Ruy Braga propõe uma interpretação diferente, que se tornou uma espécie de matriz para as análises de outros estudiosos, como Felipe Dermier, Valério Arcary e Marcelo Badaró. Situando-se à esquerda do governo destituído, esses autores argumentam que junho 2013 deve ser lido como o resultado dos equívocos políticos dos governos petistas, que ao se alinharem aos interesses do grande capital acabaram produzindo uma massa de trabalhadores urbanos precarizados, que insatisfeitos com sua inserção no mercado de trabalho e com a baixa qualidade de vida nas grandes cidades teriam protagonizado as "Jornadas":

2013 assistiu a convergência espontânea entre a luta política do precariado urbano manifestando-se nas ruas em defesa dos seus direitos sociais e a luta econômica da classe trabalhadora mobilizada sindicalmente em defesa de melhores salários e condições de trabalho. Em outras palavras, a 
O significado do conceito "corrupção" na semântica política...

combinação dessas duas dimensões das lutas de classes no país terá atingido simultaneamente tanto o modelo de regulação quanto o regime de acumulação que sustentam a reprodução do atual modelo de desenvolvimento capitalista brasileiro, anunciando o colapso do lulismo como estratégia de pacificação social (BRAGA, 2016. p. 71).

Já o cientista político André Singer argumenta que nos seus primeiros momentos as "Jornadas de 2013" foram movidas pela aliança entre frações da classe média e o novo "precariado" do qual fala Ruy Braga. Singer acredita que o que levou a classe média tradicional e o precariado às ruas foi a conjugação entre problemas típicos da vida nas grandes cidades, como trânsito caótico, violência e baixa qualidade nos serviços públicos. Esse cenário teria dado origem a uma "situação de mal-estar geral", que aglutinou os manifestantes através de uma agenda negativa, o que explicaria o caráter fluído das "jornadas", que desde os primeiros momentos não apresentaram uma pauta programática mais clara.

A despeito das divergências interpretativas, os autores, assim como outros intérpretes dos acontecimentos ${ }^{1}$, apontam o dia 2 de junho de 2013 como o momento de inauguração das "Jornadas de 2013”. Foi neste dia, uma quinta-feira, que a Prefeitura de São Paulo, governada na época por Fernando Haddad, do Partido dos Trabalhadores, anunciou um aumento na tarifa dos transportes urbanos. Esse foi o gatilho para que o Movimento Passe Livre, o MPL, colocasse em curso um modus operandi que já caracterizava a atuação pública do grupo desde meados dos anos 2000: arregimentação de jovens universitários através de redes sociais, com a posterior organização de ocupações em espaços públicos estratégicos, com o objetivo de fortalecer a agenda de protestos e conquistar o apoio da sociedade civil. Em um trabalho específico sobre os movimentos sociais no Brasil contemporâneo, a socióloga Ilse Warren afirma que a pauta do MPL jamais se restringiu ao tema das tarifas dos transportes públicos, estando relacionada aos direitos dos cidadãos em uma perspectiva bastante ampliada, o que envolve "a mobilidade urbana de uma forma geral, que deveria ser considerada como um direito fundamental, tal como o direito à educação, à saúde" (SCHERER, 
2012, p. 141). Em síntese: é possível dizer que as “Jornadas de 2013” não nasceram como jornadas, mas sim como o resultado da ação já conhecida, de um movimento social já conhecido, que tinha sua razão de ser baseada na ideia de "direito à cidade".

No dia 11 de junho de 2013, os manifestantes voltaram às ruas na capital paulista em um protesto que reuniu cerca de 15 mil pessoas. A essa altura, os ânimos estavam exaltados e já podíamos encontrar na imprensa notícias de repressão violenta por parte das forças policiais, o que trouxe para a cena dos protestos outros atores e movimentos, como, por exemplo, os black blocs. A partir desse segundo momento, os protestos populares já ganham o formato de uma "jornada", com grande capacidade de mobilização social, que foi impulsionada pelo fato de que naqueles dias o Brasil estava no centro das atenções da imprensa internacional, em virtude da realização da Copa das Confederações. O mais importante para os meus interesses neste artigo é o perfil social dos manifestantes e as suas agendas principais, pois reside aqui um aspecto central para a compreensão da crise. Entre 2013 e 2016, o perfil social dos protestos populares e as suas agendas modificaram-se profundamente, o que sugere uma reorientação das ruas, à luz de uma narrativa baseada na hipertrofia de um significado específico da ideia de corrupção.

Segundo as pesquisas realizadas por diversos institutos em várias capitais brasileiras entre 17 e 20 de junho, o perfil médio dos manifestantes pode ser resumido da seguinte forma, com diferenças regionais que não comprometem a tipologia geral que estou apresentando: jovens entre 15 e 24 anos, escolarizados e com renda familiar situada entre dois e cinco salários mínimos ${ }^{2}$. Nesse primeiro momento da crise, a agenda dos manifestantes estava pautada nas ideias de "direito à cidade", de "participação política direta" e de "horizontalidade na organização dos movimentos sociais", o que sugere que a essa altura o MPL ainda controlava o rumo das manifestações.

Ainda há muito a ser estudado sobre o início das "Jornadas de 2013”, cuja compreensão não se esgota em tabelas e dados quantitativos. Por ora, é importante compreender a atuação da imprensa hegemônica, que formulou uma narrativa de interpretação da crise 
O significado do conceito "corrupção" na semântica política...

que foi determinante para o delineamento de uma determinada chave de leitura dos acontecimentos.

\section{A atuação da grande imprensa e as mudanças no curso da crise}

Não é de hoje que, na condição de detentora do monopólio da informação, a mídia hegemônica brasileira é um ator relevante na vida política nacional. $O$ poder que aquela tem para interferir diretamente na formação da opinião pública ficou especialmente claro no atual cenário de crise, onde os principais veículos de comunicação, em uníssono, reorientaram os rumos dos protestos populares, contribuindo para a modificação da sua composição social e da sua agenda programática. Se tomarmos o noticiário "Jornal Nacional" da Rede Globo como fonte, perceberemos claramente esse esforço de reorientação e de produção de uma narrativa midiática que influenciou diretamente os desdobramentos da crise.

Entre 7 e 12 de junho, quando, como demonstrei há pouco, os protestos populares já movimentavam a capital paulista, o "Jornal Nacional" tratou os eventos como "distúrbios provocados por vândalos com pouca capacidade de mobilização social”. No dia 7 de junho, o editorial do noticiário global dizia o seguinte:

Durante um protesto contra o reajuste de $\mathrm{R} \$ 3$ para $\mathrm{R} \$ 3,20$ nas passagens de ônibus e do metrô, começou a violência. No Anhangabaú, centro da cidade, manifestantes atearam fogo em cones. Depois caminharam em direção à Avenida Paulista, onde houve o primeiro confronto com os policiais. Uma cabine da polícia foi jogada ao chão. Uma lixeira de concreto foi usada como barreira. Bombas de gás, tiros para o alto e rojões pipocavam entre policiais e manifestantes. $O$ vandalismo assustou quem trabalha na região. [...] A avenida mais famosa de São Paulo ficou irreconhecível. As placas de madeira cobrem o que foi destruído da entrada desta estação do metrô. A companhia diz que o prejuízo foi de $R \$ 73$ mil só com lâmpadas e vidros quebrados. $O$ valor que vai ser gasto com o conserto é o mesmo da venda de bilhetes para que 22.812 passageiros façam apenas uma 
viagem. Nesta sexta-feira, durante o dia, tudo começava a voltar ao normal na Avenida Paulista. Na Zona Oeste, a situação ainda era agitada na noite desta sexta-feira. A polícia mantém o bloqueio (JORNAL NACIONAL, 2013, grifo nosso).

O tom da cobertura feita por outros veículos, em outras emissoras, era muito parecido com o adotado pelo JN, o que também não é de causar surpresas, visto o monopólio da informação que caracteriza a imprensa brasileira. No entanto, na edição do JN que foi ao ar no dia 13 de junho já é possível perceber uma sensível mudança, que na época passou despercebida, mas que hoje, vendo daqui, na confortável posição de quem já sabe o que aconteceu, é um claro indicativo da operação semântica que a grande imprensa brasileira começava a pôr em movimento. Tratou-se da menção, pela primeira vez, à PEC 37, que como mostram as pesquisas de opinião mencionadas há pouco, não foi sequer citada pelos manifestantes envolvidos com os primeiros sopros das “jornadas de junho de 2013".

O Projeto de Emenda Constitucional 37 foi apresentada em 2011 pelo Deputado Federal Lourival Mendes (PTB-MA) e propunha a limitação da investigação criminal às alçadas das Polícias Civis dos Estados e da Polícia Federal, deixando ao Ministério Público a função exclusiva de acusar, de oferecer denúncias, como determina a própria Constituição de 1988. Por motivos que ainda não estão claros, o departamento de jornalismo da Rede Globo, a partir de 13 de junho de 2013, abriu fogo contra o projeto, dando início à aproximação entre o aparato jurídico-policial do Estado e a mídia hegemônica, constituindo a aliança que, ao menos na minha interpretação, representa a mais poderosa entre as forças envolvidas na crise brasileira. A partir desse pontapé inicial, não foram necessárias nem vinte e quatro horas para que o departamento de jornalismo da Rede Globo modificasse drasticamente a sua forma de tratar os protestos populares. Já na edição do "Bom Dia Brasil”, que foi ao ar na manhã do dia 14 de junho, a chamada da reportagem sobre os protestos populares que aconteceram no dia anterior na capital paulista era: "Polícia Militar utiliza violência para reprimir 
O significado do conceito "corrupção" na semântica política...

protesto em São Paulo”. O conteúdo da reportagem aponta para a reorientação da narrativa:

Uma noite de violência e pânico em São Paulo. O quarto dia de protestos contra o aumento da tarifa do transporte público transformou as ruas da maior cidade do país em um cenário de guerra. Foram seis horas de protesto. Dessa vez, a polícia endureceu a repressão, agindo com violência. Duzentas pessoas foram detidas e dezenas ficaram feridas. Muita gente que não fazia parte do protesto também ficou no meio de tiros e pedras. No quarto dia de protestos contra o aumento da tarifa de ônibus, a repressão policial foi mais intensa. Uma noite que terminou com mais de 200 presos, muitos feridos, e população assustada. Não era o que o movimento pedia (BOM DIA BRASIL, 2013, grifo nosso).

Os manifestantes não são mais representados como vândalos, mas sim como cidadãos comprometidos com as pautas consideradas fundamentais para o desenvolvimento do país, como "a melhoria nos serviços públicos e o combate à corrupção”. Está aqui, pela primeira vez, a palavra-chave, sendo associada, obviamente, à PEC 37, definida por Alexandre Garcia, jornalista que na época era o comentarista político do BDB, como "[...] uma estratégia da classe política para sufocar as instituições responsáveis pelo combate à corrupção" (IDEM). Cada vez mais, essa narrativa seria desenvolvida, até que foi plenamente sistematizada no dia 3 de julho, na edição 2328 da "Revista Veja", com a entrevista cujo trecho serviu como epígrafe a este artigo.

A essa altura, a mídia hegemônica já tinha um discurso para chamar de seu: a crise era o resultado da corrupção organizada e institucionalizada pelos governos petistas. A agenda original das "Jornadas de junho", relacionadas, como já sabemos, à ideia de "direito à cidade", foi transformada numa outra coisa, em algo distante, até desaparecer por completo da cobertura jornalística. Percebendo o que estava acontecendo, as lideranças do MPL decidiram sair de cena, no dia 21 de junho. Em entrevista à Rádio CBN, Douglas Beloni, um dos coordenadores do movimento, disse que: 
O movimento não vai convocar novas manifestações. Infelizmente, o PT convocou um protesto para o mesmo local, que acabou atrapalhando o andamento da comemoração de ontem (quinta-feira), mas também houve uma hostilidade a outros partidos que estavam desde o início compondo luta contra o aumento. Então, nós entendemos que foi uma avaliação errada feita pelos manifestantes e condenamos a prática. [...] O movimento não deve mais convocar manifestações, levando em conta algumas pautas conservadoras que foram levantadas. Por exemplo, algumas pessoas pediam a redução da maioridade penal. A bandeira do movimento é por transporte público (O GLOBO, 2013).

A tentativa foi em vão, pois já era tarde demais para voltar atrás. O refluxo do MPL não atenuou em nada os protestos populares, que se tornaram ainda mais inflamados e distantes dos seus propósitos iniciais. $\mathrm{O}$ perfil social dos manifestantes mudou, assim como o conteúdo programático das manifestações.

\section{Os novos ventos da crise e as práticas políticas liberais conservadoras}

\section{A segunda fase das manifestações populares}

Como já comentei antes, ainda hoje, estamos vivemos sob a experiência de crise que começou em 2013. Contudo, seria um gravíssimo equívoco de análise afirmar que o sentido da crise permanece o mesmo. Lá em 2013, os protestos não estavam majoritariamente direcionados contra o governo comandado pelo Partido dos Trabalhadores, o que não é verdade para o período posterior a janeiro de 2015. Se, por um lado, o governo chefiado por Dilma Rousseff não teve força política suficiente para responder às demandas apresentadas pelas ruas em junho de 2013, por outro, os ataques, cada vez mais agressivos e orquestrados pela aliança entre a oposição parlamentar, o aparato jurídico-policial do Estado e a mídia hegemônica, não foram o bastante para derrotar a petista nas eleições realizadas em 
outubro de 2014. Com a vitória de Dilma Rousseff e com a eleição de um parlamento dominado pela oposição ao reformismo petista, esgotou-se a última possibilidade de resolução da crise nos quadros da institucionalidade vigente.

A partir de janeiro de 2015, portanto, quando teve início o segundo mandato de Rousseff, o cenário de crise só se agravou, evoluindo rapidamente até a ruptura institucional no segundo semestre de 2016, com o controverso impeachment da Presidenta eleita. Ao longo desses dois anos, as ruas das principais cidades brasileiras estiveram frequentemente ocupadas, em um processo que apenas aparentemente pode ser definido como uma continuidade das "Jornadas de Junho de 2013”. Para o sociólogo Cláudio André de Souza, apesar das diferenças entre os perfis sociais dos manifestantes de 2013 e de 2015, é possível perceber semelhanças entre as duas ondas de protestos, na medida em que algumas das pautas permaneceram postas na mesa do debate público, como, por exemplo, a melhoria na qualidade dos serviços públicos. As semelhanças, entretanto, terminam aí. Segundo os dados apresentados pela pesquisa realizada pelo Instituto Data Folha em diversas capitais brasileiras no dia 15 de março de 2015, quando aconteceu o primeiro grande protesto popular dessa segunda onda de mobilização social, uma considerável parte dos manifestantes $(82 \%)$ era constituída por eleitores de Aécio Neves, enquanto $37 \%$ possuíam preferência partidária pelo PSDB; 74\% estavam em uma manifestação pela primeira vez e 76\% tinham ensino superior completo; 63\% contavam mais de 35 anos e $52 \%$ possuíam renda familiar superior a dez salários mínimos. Ou seja, temos aí um público mais velho, mais escolarizado e com maior poder aquisitivo do que aquele que protagonizou os eventos de junho de 2013.

Entre os dados apresentados por essa pesquisa, dois são especialmente relevantes para o argumento que estou desenvolvendo neste ensaio: 77\% se diziam decepcionados com o PT e 87\% consideravam a legenda a mais corrupta do sistema político brasileiro. Aqui fica clara a presença de uma agenda que estava ausente na pauta originária de junho de 2013: a associação entre o petismo e a institucionalização da corrupção, uma relação que não era exatamente nova, na medida em que já estava presente no imaginário 
político de parte da sociedade brasileira, pelo menos, desde 2005, na ocasião da crise do "Mensalão", que não chegou a evoluir para um cenário de crise institucional tão grave como o que estamos vivendo hoje. Mas, o que os manifestantes estavam entendendo por "corrupção"?

\section{Sobre o conceito "corrupção"}

O termo "corrupção" pode ter diversos significados, a depender do repertório político em que for inserido. Dedicar alguma atenção ao significado específico que esse conceito ganhou na dinâmica da crise brasileira nos ajuda a compreender os contornos da semântica política liberal conservadora da qual estou falando desde o início deste artigo. Ao ser alçado ao primeiro plano da crise, o termo "corrupção" foi associado ao princípio da propriedade, que é, como sabemos, um dos valores mais importantes da modernidade ocidental. Não é nada difícil encontrar evidências que comprovem a centralidade desse significado de corrupção na dinâmica da crise brasileira. Basta uma pesquisa rápida no Google para tropeçarmos em entrevistas e vídeos com pronunciamentos dos manifestantes que participaram dos protestos populares realizados entre janeiro de 2015 e meados de 2016. Esses pronunciamentos sugerem que essas pessoas ocuparam as praças de protestos porque estavam convencidas de que os governos petistas haviam levado a corrupção a níveis de organização institucional e grandeza nunca antes vistos na história do Brasil.

Certamente, quando uma dessas pessoas gritava ferozmente contra a "corrupção dos governos petistas", ela não estava se movendo dentro da semântica marxista, segundo a qual a corrupção nos quadros do Capitalismo não passa de mera redundância. Marx tratou especificamente do problema da corrupção no livro A luta de classes em França de 1848 a 1850, publicado pela primeira vez em 1851. Para Marx, a corrupção é uma condição essencial do sistema político burguês, estruturado, sempre, para atender o desejo de "enriquecer não através da produção, mas sim através da sonegação de riqueza alheia já existente” (MARX, 2014, p. 43). Corrupto, então, segundo Marx, não é, exatamente, o político profissional 
que se apropria indevidamente do dinheiro público, mas, sim, o regime de poder burguês que não possibilita ser virtuoso. Quando um jornalista como Merval Pereira afirma que os governos petistas "generalizaram a roubalheira", o conceito corrupção não está sendo tratado na perspectiva republicana, onde a corrupção é definida como o desvirtuamento político e institucional da República, não estando associada, diretamente, ao uso indevido dos recursos públicos. Aristóteles, por exemplo, no tratado Política, definiu a corrupção como o efeito natural do tempo sobre os sistemas políticos. Nos seus Discorsi, Maquiavel, seguindo a trilha aberta por Aristóteles, definiu a corrupção como a perda da capacidade da República em institucionalizar os seus conflitos. Uma República corrompida, portanto, tanto para Aristóteles como para Maquiavel, não seria, exatamente, aquela na qual os seus governantes roubam dinheiro público, mas, sim, aquela que se tornou incapaz de limitar os conflitos entre os seus cidadãos à esfera da institucionalidade. Quando isso ocorre, os apetites pessoais tornam-se incontroláveis e a comunidade política morre.

A semântica política liberal conservadora que se popularizou no Brasil na dinâmica da crise institucional que começou em junho de 2013, e que inspirou as práticas políticas dos atores sociais que se envolveram diretamente nos ataques ao governo chefiado por Dilma Rousseff, tem numa certa gramática liberal o seu núcleo duro. Para compreender melhor as especificidades dessa gramática liberal, é necessário recorrer, ainda que brevemente, aos escritos de Friedrich Hayek, um dos mais importantes teóricos do liberalismo. O slogan "ética na política” é tratado por Hayek em referência a deveres de caráter negativo, segundo os quais o governante virtuoso, honesto, "não deve proceder de forma a intervir na integridade física e nos direitos de propriedade de outros, não deve descumprir suas promessas e contratos válidos, não deve agir de forma desonesta ou fraudulenta, não deve se apropriar dos recursos públicos para fins privados" (HAYEK, 2009, p. 62). Temos aqui uma noção de honestidade, e, por consequência lógica, de corrupção, circunscrita à ação individual. O sujeito, em última instância, é soberano de sua própria ação e a ética política nada mais é do que a normatização da conduta individual dentro de parâmetros que partem da premissa 
de que a propriedade, seja ela pública ou privada, é inviolável. Segundo o cientista político espanhol Roberto Rodriguez Guerra, essa vertente do liberalismo, representada por autores como Hayek e Ludwig von Mises, evoca uma concepção de "justiça procedimental", segundo a qual caberia ao Estado Liberal apenas o planejamento e a execução de medidas que permitissem aos indivíduos atingirem, usando seus próprios meios, os seus objetivos individuais. Guerra chama esse liberalismo de "conservador".

O que Guerra chama de liberalismo conservador, o cientista político brasileiro Álvaro de Vita chama de "liberalismo deontológico", que tem como alicerce uma noção de virtude individual que "se exprime por meio de interdições deontológicas - deveres negativos de caráter não excepcionável - que se impõem às linhas de ação que podem ser adotadas pelos agentes, em especial quando se trata do exercício do poder político" (VITA, 2012, p. 80). Para o liberalismo deontológico, a corrupção está associada exclusivamente ao poder público, à sua autoridade para interferir na livre competição entre os indivíduos. Nesse sentido, quanto maior for o tamanho do Estado, mais pessoas terão alguma possibilidade de interferir na livre competição social, o que acabará corrompendo a sociedade, uma vez que os indivíduos terão que direcionar os esforços que deveriam estar completamente dedicados à livre competição social para a cooptação dos agentes políticos.

Está exatamente aqui, nesse liberalismo deontológico, a semântica que se tornou o elemento fundamental da crise brasileira. Seria equivocado, entretanto, sugerir que o termo "liberalismo", em si, seja capaz de dar conta dos valores políticos que constituem a arquitetura ideológica da crise, como se o "liberalismo" fosse uma única tradição política que desde o início da modernidade se manteve estática, estando sempre a serviço dos interesses burgueses. O cientista político italiano Nicola Tranfaglia demonstra que o liberalismo não deve ser tratado como uma "família do pensamento político ocidental", mas sim como um "um fenômeno histórico que se manifesta na idade moderna e que tem seu baricentro na Europa, e que desde o século XVI é objeto de disputas nos mais diversos espectros do jogo político ocidental" (TRANFAGLIA, 1995, p. 687). $\mathrm{O}$ autor argumenta que a matriz original do liberalismo 
não é essencialmente burguesa, pois os vínculos entre liberalismo e burguesia somente se consolidaram no século XIX, junto com o modelo do Estado Liberal, que se tornou o arranjo institucional predileto da classe burguesa. Segundo Tranfaglia, na medida em que não está essencialmente subordinado às aspirações burguesas, uma vez que o seu o ponto de partida foram os princípios da tolerância e da liberdade privada de culto, ainda na conjuntura das guerras civis religiosas do século XVI, o liberalismo precisa ser visto mais como um conjunto de valores mais ou menos coerentes entre si do que como um sistema de pensamento fechado. O liberalismo, portanto, é cambiante, podendo se desdobrar, por exemplo, em diferentes formas de tratar o fenômeno da corrupção. Por isso, é importante especificar o tipo de liberalismo que está norteando a minha reflexão, já que num terreno tão movediço como é a análise política, toda precisão no uso dos conceitos parece pouca.

Como exemplo dessa variação semântica dentro do próprio escopo liberal, cito aquilo que Vita chama de "liberalismo de bem-estar social", que Tranfaglia chama de "liberalismo ético" e que Guerra chama de "liberalismo social". Os três autores evocam o revisionismo do repertório liberal feito nos anos finais do século XIX, quando as mudanças nos sistemas políticos ocidentais, como o surgimento das democracias de massa e dos movimentos sindicais, fizeram com que muitos doutrinadores liberais reconhecessem a importância da adoção de mecanismos mais eficientes de regulação, levando ao questionamento do princípio do laissez-faire, tão caro ao liberalismo clássico. Para Roberto Guerra,

A ideia do livre mercado, para alguns liberais do final do século XIX e do início do século XX, mostrou-se incapaz de harmonizar os diferentes e concorrentes interesses em jogo para alcançar o progresso esperado de todos, sendo também incapaz de preservar a estabilidade social mínima exigida para a manutenção e desenvolvimento da sociedade liberal-capitalista (GUERRA, 1998, p. 40-41).

O filósofo britânico John Stuart Mill foi um dos primeiros a apontar a insuficiência do liberalismo clássico e defender a 
atenuação do laissez-faire através do fortalecimento de mecanismos regulatórios, em um movimento de revisão da doutrina liberal que chegou a John Maynard Keynes, passando por Thomas Hill Green e por Leonard Trelawney Hobhouse. Para esse "liberalismo social”, a corrupção não está exatamente relacionada a uma ética instrumental e individual, pois aqui a ausência de constrangimentos para o livre exercício da vontade não é o suficiente para definir a liberdade política. A corrupção, então, é definida de outra forma, não exatamente como o cerceamento da livre competição social. Para Álvaro Vita, nessa variante do liberalismo político,

[...] a ética na política não significa somente fazer com que se cumpra um rol de interdições deontológicas que se aplicam à conduta de cidadãos individuais e de agentes públicos, e sim diz respeito, essencialmente, aos esforços que os cidadãos e seus representantes devem realizar para tornar os arranjos institucionais básicos de sua sociedade um "procedimento justo" (VITA, 2012, p. 81).

Nesse sentido, no liberalismo revisado, a métrica da ética na política não se refere ao comportamento individual do agente político, mas, sim, ao esforço da sociedade civil e da classe política no sentido do fortalecimento das instituições que sejam capazes de fomentar um "procedimento social justo", para que todos os indivíduos tenham iguais condições para o exercício da competição. Esse liberalismo revisionado foi criticado por uma nova vertente da ortodoxia liberal, que foi formulada de maneira mais clara durante o século XX, nos escritos de Ludwig von Mises e que foi inspirada por autores como Herbert Spencer e Gaetano Mosca. Essa ortodoxia liberal evocou o mesmo conceito negativo de liberdade que é característico do "liberalismo clássico". Spencer, por exemplo, diz que a liberdade humana não deve ser medida pela

[...] natureza do sistema de governo em que o cidadão vive, mas sim pelo número relativamente pequeno de restrições que lhe são impostas; porque independentemente se ele contribuiu ou não para a sua construção, as ações desse sistema 
O significado do conceito "corrupção" na semântica política...

não são apropriadas para o liberalismo se aumentam suas restrições para além do que é necessário para proteger o indivíduo de agressão direta ou indireta de seus concidadãos (SPENCER, 1888, p. 77).

A crítica de Mises ao revisionismo liberal é semanticamente parecida com a de Spencer, ainda que seja terminologicamente distinta. Enquanto Spencer está preocupado exclusivamente em criticar os constrangimentos institucionais que limitam a competição social, Mises denuncia o conteúdo socialista do revisionismo liberal, que segundo ele poderia ser percebido nos textos de Keynes. O fundamental aqui é que, mesmo com suas diferenças, os diversos autores que reforçaram a ortodoxia liberal compartilham a mesma rejeição ao Estado, visto sempre com desconfiança, como campo fértil para a corrupção, como o poder que é potencialmente corruptor, na medida em que desvirtua a sociedade civil daquele que seria o seu destino manifesto: a livre competição, segundo a qual cada indivíduo persegue com meios próprios sua felicidade pessoal. $\mathrm{O}$ antiestatismo liberal, que tende a naturalizar as desigualdades sociais, tornou-se, segundo Pierre Dardot e Christian Laval, a nova razão do mundo a partir dos anos 1980. Mas, como demonstra Roberto Guerra, esse repertório já estava disponível no mundo ocidental desde a primeira metade do século XX e já circulava na cena política brasileira nos anos 1990, quando, na minha interpretação, é possível situar a ancestralidade semântica da crise contemporânea.

\section{A ancestralidade da crise brasileira: o transformismo tucano nos anos 1990}

O PSDB foi fundado em 1988 por um grupo de lideranças políticas dissidentes que se definiam como "críticos de esquerda" ao PMDB que na época governava a República com José Sarney. A criação do PSDB já foi objeto de diversos estudos, que apresentam, basicamente, duas interpretações diferentes. A primeira interpretação, desenvolvida por autores como Maria D’Alva Kinzo, Celia Melhen e 
Boliva Lamounier, destaca as motivações ideológicas dos fundadores do PSDB. Esses estudiosos afirmam que, desde meados da década de 1980, alguns parlamentares do PMDB estavam insatisfeitos com a cúpula do partido, que estreitava laços com a "direita fisiológica e oligárquica", na época representada pelo Partido da Frente Liberal, o PFL, visando o boicote ao calendário eleitoral, com a tentativa de ampliação do mandado presidencial de Sarney. Segundo Célia Melhen, as relações entre os parlamentares dissidentes e o PMDB ficou insustentável a partir de 1986, em virtude do "predomínio de Orestes Quércia na política paulista, o que fez com que jovens lideranças perdessem espaço”. Para Bolívar Lamounier, a gota d'água para a ruptura veio em 1988, na ocasião das eleições municipais paulistas, quando o PMDB apresentou a candidatura do engenheiro João Leiva, articulada pela aproximação entre políticos conservadores do PFL e Jânio Quadros, então prefeito da capital paulista. Essa articulação teria marginalizado as novas lideranças progressistas do PMDB, com destaque para Fernando Henrique Cardoso.

Interpretação alternativa foi apresentada por Celso Roma, para quem a fundação do PSDB não foi motivada por convicções ideológicas, mas, sim, por um cálculo eleitoral pragmático que explica, em parte, as estratégias políticas adotadas pelo partido ao longo da década de 1990. Examinando especificamente a organização partidária do PSDB, Roma afirma que o novo partido

[...] foi criado por parlamentares em busca de espaço de poder, portanto, a partir de uma ação estratégica pragmática. Sua criação como partido interno ao sistema parlamentar propiciou uma estrutura organizacional fraca, descentralizada, a inexistência de atividades extra eleitoral e pequena participação dos filiados e a falta de instâncias democráticas de veto às decisões das elites dirigentes. Essa estrutura, por sua vez, facilitou a aproximação entre o partido e o PFL, principalmente porque o programa de governo de ambos os partidos apresenta uma visão ideológica próxima do liberalismo (ROMA, 2002, p. 72). 
O significado do conceito "corrupção" na semântica política...

Seja como for, o resultado de uma dissidência progressista dentro do PMDB ou como o produto de um cálculo pragmático de algumas lideranças, ou mesmo as duas coisas juntas, o fato é que o PSDB nasceu em 1988 e em pouco tempo tornou-se um dos mais poderosos partidos do sistema político brasileiro, com destacado desempenho eleitoral. Estou interessado, especialmente, nas manifestações discursivas de algumas lideranças do partido em dois momentos específicos: a fundação da legenda e as eleições presidenciais realizadas em 1994, que foram vencidas pelo PSDB, por Fernando Henrique Cardoso. O liberalismo conservador, de matriz antiestatista, foi largamente mobilizado nesses dois momentos, sob a forma da rejeição ao corporativismo getulista, definido sempre de forma pejorativa com o termo "populismo".

No momento da criação do PSDB, o sociólogo carioca Hélio Jaguaribe, em artigo publicado no jornal "Folha de São Paulo", definiu da seguinte maneira os objetivos do novo partido:

\begin{abstract}
A social democracia é a síntese teórica e histórica que superou as limitações do capitalismo do século XIX e os aspectos inaceitáveis do socialismo estatizante. A essência do modelo social-democrático consiste na preservação de uma economia de mercado, com todo o dinamismo e a criatividade da iniciativa privada, submetendo-a, através de um Estado democrático, limitado no seu tamanho e vacinado contra a corrupção, a um controle social. É essa grande síntese, que reúne o legado positivo das experiências e ideias da economia de mercado com o da justiça social, que o PSDB se propõe a realizar, nas condições brasileiras (JAGUARIBE, 1990).
\end{abstract}

Outra vez podemos perceber, com alguma clareza, a associação entre a "limitação do Estado" e o "combate à corrupção", que, como já disse antes, é uma tópica fundamental do conservadorismo liberal antiestatista. A mesma tópica foi formulada por Fernando Henrique Cardoso, também em 1990, quando o PSDB começava a se projetar como um dos mais poderosos partidos políticos em atuação no poder Legislativo. 
É preciso reconhecer que a tradição social-democrática de basear sua força na crítica das desigualdades provocadas pelo mercado (isto é, pela livre exploração da força de trabalho e pela acumulação de capitais), que devem ser corrigidas por políticas sociais e fiscais, esbarra com a vaga do liberalismo triunfante. [...] A social democracia desloca, portanto, o eixo da opção entre estatal ou privado do plano ideológico para um plano objetivo: importantes são as condições que devem ser criadas para o funcionamento da economia. A gestão predadora, patrimonialista, e a corrupção podem existir no setor estatal ou privado. Ambas são condenáveis. Mas no setor estatal seus impactos são ainda mais cruéis. $\mathrm{O}$ mercado competitivo e a diminuição do Estado é o antídoto para esses males (CARDOSO, 1990).

Aqui é preciso ter algum cuidado para não vincular de maneira mais apressada a agenda política do primeiro tucanismo ao neoliberalismo internacional, tal como foi formulado em 1989 no "Consenso de Washington”. Como mostro a seguir, o vínculo do PSDB com as diretrizes apresentadas pelo Consenso de Washington somente ficaria mais claro na campanha eleitoral de 1994, quando Fernando Henrique Cardoso assumiu publicamente o seu compromisso com as medidas sugeridas pelo Fundo Monetário Internacional, pelo Banco Mundial e pelo Departamento de Tesouro dos EUA. Até então, havia o esforço das principais lideranças do partido em se desvincular do neoliberalismo internacional, como verbalizou Bresser Pereira, também em 1990:

Desde quando eliminar monopólios estatais, desde quando diminuir o Estado para diminuir a corrupção, desde quando eliminar privilégios na previdência e recuperar seu equilíbrio financeiro, desde quando reformar o aparelho de Estado e tornar a burocracia mais responsável perante o governo e a nação, desde quando abrir o país de forma pragmática, desde quando lutar dia-a-dia pelo ajuste fiscal e a estabilidade da moeda é estar engajado em reformas neoliberais? (PEREIRA, 1990). 
O significado do conceito "corrupção" na semântica política...

No primeiro tucanismo, portanto, as reformas administrativas destinadas à "racionalização" da máquina pública, ao encolhimento do Estado, não eram legitimadas apenas com argumentos de teor econômico ou financeiro, mas, sobretudo, com argumentos de teor ético, baseados no binômio honestidade X corrupção. Diminuir o Estado significaria reduzir a quantidade de cargos públicos, a quantidade de dinheiro disponível para desvios e negociatas e, principalmente, reduzir capacidade do poder público em tutelar e corromper a sociedade civil. O programa político do primeiro tucanismo, então, defendia aquilo que Fernando Henrique Cardoso chamava de "ativação da sociedade civil", que consistia na criação de mecanismos de atuação, no desenvolvimento de uma "cultura da participação”, que permitissem à sociedade civil a livre manifestação, fora da tutela do Estado. Para isso, seria fundamental, ainda nas palavras de Fernando Henrique Cardoso, "confrontar não apenas o legado do autoritarismo dos militares, mas a herança do autoritarismo burocrático e populista criado por Getúlio Vargas e que ao longo dos anos sufocou qualquer possibilidade de desenvolvimento autônomo, que corrompeu a livre iniciativa da sociedade civil” (CARDOSO, 1990). O “autoritarismo burocrático e populista getulista” seria, então, na avaliação de Fernando Henrique Cardoso, a matriz do autoritarismo brasileiro e para combatê-lo era "urgente modernizar as instituições públicas, diminuí-las, para combater a corrupção e fazer a sociedade respirar” (CARDOSO, 1990).

É importante lembrar que a crítica ao "autoritarismo burocrático e populista getulista" não era uma prerrogativa tucana, mas, sim, uma das principais narrativas da redemocratização, que vinha sendo formulada em importantes instituições intelectuais, como o Centro Brasileiro de Análise e Planejamento, o CEBRAP, de onde saíram diversas lideranças do PSDB, e o Centro de Estudos de Cultura Contemporânea, o CEDEC, de onde saíram os principais quadros intelectuais que se engajaram diretamente na fundação do Partido dos Trabalhadores, em 1980. Estou afirmando, portanto, que tanto tucanos como petistas, nos debates públicos que marcaram a redemocratização brasileira, criticaram o trabalhismo corporativo, consolidado ao longo dos anos 1950 pela aliança entre o Partido Trabalhista Brasileiro, o PTB, e o Partido Comunista Brasileiro, 
o PCB. No entanto, não se tratava, exatamente, da mesma crítica, pois o "novo sindicalismo" petista confrontava especificamente a cooptação dos sindicatos pela máquina pública. Essa crítica explica, em parte, os vigorosos embates públicos travados entre Luiz Inácio Lula da Silva e Leonel Brizola, principal herdeiro do trabalhismo corporativo, ao longo das décadas de 1980 e 1990. Por outro lado, a crítica tucana, como sabemos, era dirigida diretamente às instituições do Estado, definidas como naturalmente corrompidas e corruptoras. Foi nas eleições de 1994, porém, mais especificamente na campanha de Fernando Henrique Cardoso para a Presidência da República, que o liberalismo conservador tucano começou a pautar o debate público brasileiro, agora sim, associado diretamente ao neoliberalismo internacional, às orientações do Consenso de Washington.

As eleições presidenciais realizadas em 1994 foram marcadas pelas discussões a respeito das diretrizes econômicas formuladas no Consenso de Washington. De um lado, a candidatura de Fernando Henrique Cardoso defendia abertamente a adesão às normas de austeridade estabelecidas em Washington, o que firmou os vínculos entre o PSDB e a agenda do neoliberalismo internacional, configurando aquilo que estou chamando de "último tucanismo". Do outro lado, as candidaturas de Lula e Leonel Brizola, cada uma a seu modo, opunham-se ao que consideravam um ataque neoliberal à soberania nacional. As noções de "populismo" e "corrupção" atravessaram a disputa eleitoral, que foi travada nos grandes meios de comunicação da época, em especial os jornais "Jornal do Brasil", "Folha de São Paulo" e "Estadão". De alguma forma, a vitória de Fernando Henrique Cardoso, no primeiro turno das eleições, marcou a vitória da cultura política liberal conservadora de viés antiestatista, constituída pelas mesmas tópicas que hoje são fundamento semântico da crise brasileira. Temos aqui, de alguma maneira, a ancestralidade da atual experiência de crise.

A agenda neoliberal formulada no Consenso de Washington já estava presente no cenário político brasileiro desde o final dos anos 1980. A expectativas das forças comprometidas com essa agenda era que o Fernando Collor de Mello, eleito Presidente da República em 1989, levasse a cabo as "reformas estruturais modernizantes”, que no vocabulário neoliberal consistiam, entre outras 
coisas, num rígido programa de privatizações e austeridade fiscal. A crise política que resultou, em 1992, no impeachment de Collor interrompeu a consolidação desse projeto, que ficou praticamente paralisado durante o governo tampão de Itamar Franco. Já no calor da disputa presidencial de 1994, o economista Luís Carlos Bresser-Pereira, um dos principais consultores da campanha de Fernando Henrique Cardoso e o mais importante defensor das diretrizes estabelecidas pelo Consenso de Washington, dizia que "em ambas as regiões [América Latina e Leste europeu], o ajustamento estrutural - ou seja, a muito necessária reforma do Estado - está sendo realizada. Estas reformas são fundamentais para o combate à corrupção, doença endêmica nessas regiões. Quanto maior o Estado maior o nível de corrupção" (PEREIRA, Folha de São Paulo: 10 de abril de 1994). O mesmo argumento, a mesma associação entre o tamanho do Estado e a prática da corrupção, pode ser encontrado na defesa que Roberto Campos (1917-2001), defensor histórico da agenda neoliberal, fez da candidatura de FHC.

A corrupção do Orçamento e das empreiteiras não é apenas uma depravação conjuntural e sim uma deformação estrutural. O principal motivo é o excessivo tamanho do governo, que faz com que muitas empresas não possam sobreviver sem as boas graças do Leviatã. [...] Cassar mandatos de congressistas ou botar uma dúzia de empresários na cadeia satisfaz temporariamente os reclamos de justiça. Mas a corrupção voltará se não aplicarmos um tríplice remédio: [...] redimensionamento do governo, pela privatização e desregulamentação (CAMPOS, 1994).

Como fica claro nas manifestações de dois dos mais importantes entusiastas da candidatura de Fernando Henrique Cardoso, a agenda neoliberal de privatizações e o enxugamento da máquina pública foram legitimados nas eleições de 1994 não apenas por uma narrativa economicista, que externava as preocupações com o equilíbrio das contas públicas e com o estabelecimento de um "clima favorável aos investimentos". A agenda neoliberal foi legitimada, também, por uma narrativa que evocou as ideias de "corrupção" 
e "ética", afirmando a diminuição do Estado como a única saída para a solução do "patrimonialismo", definido como a principal mazela da nação. Em janeiro de 1995, na ocasião de sua posse, o Presidente FHC discursou no Congresso Nacional, e mais uma vez podemos ver o liberalismo conservador antiestatista em movimento, adiantando aquela que seria a grande agenda do novo governo.

Estou convencido de que a agenda de modernização do País nada tem em comum com um desenvolvimentismo à moda antiga, baseado no populismo econômico, no descontrole dos gastos, na corrupção endêmica e no forte intervencionismo estatal. Por isso, serei inflexível na defesa da disciplina fiscal e monetária, [...], e persistente na remoção dos regulamentos [...] que travam a competição, inibem a criatividade da iniciativa privada e estimulam a corrupção. [...] O Estado não sai de cena. Muda de papel. Suas funções de produtor direto passam para segundo plano, enquanto se reforça a autoridade pública para regular [...] as atividades transferidas para a iniciativa privada (CARDOSO, 1995).

As eleições de 1994 decretaram, portanto, a vitória de uma determinada interpretação do Brasil. O binômio honestidade X corrupção estava no centro dessa interpretação. Nesse sentido, levando em conta as especificidades da atual experiência de crise, estou convencido de que é possível afirmar que a associação entre a espetacularização midiática dos escândalos de corrupção e a imposição de uma agenda legislativa voltada ao desmonte do Estado não é exatamente uma novidade, mas, sim, um projeto que já tem vida longa na história política brasileira. Após um momento inicial de sucesso político, com as eleições de Fernando Collor de Melo e de Fernando Henrique Cardoso, essa interpretação amargou uma década de contundentes derrotas eleitorais, que marcaram, também, a ascensão do reformismo petista ao controle do Estado brasileiro. $\mathrm{Na}$ atual conjuntura de crise, esse liberalismo conservador antiestatista tornou-se, novamente, o mais poderoso projeto em curso na política nacional. Essa força, entretanto, não veio das urnas, da soberania popular, mas sim de um controverso processo de impeachment, que alguns ainda insistem em chamar de "golpe". 
O significado do conceito "corrupção" na semântica política...

\section{Considerações finais}

Interpretar a crise brasileira no calor da própria crise coloca o historiador diante de dificuldades diferentes daquelas que envolvem o estudo de eventos já pacificados pelo decurso do tempo. Essas dificuldades inerentes à tempestividade do objeto referem-se, sobretudo, à velocidade dos acontecimentos. No momento em que finalizo este artigo, o Presidente Michel Temer acaba de conquistar uma importante vitória no Congresso Nacional, que arquivou a denúncia oferecida por Rodrigo Janot, Procurador Geral da República. Janot acusou o Presidente da República dos crimes de formação de quadrilha e corrupção passiva, após a divulgação de um áudio no qual Temer estaria tramando a compra do silêncio do ex-Deputado Eduardo Cunha, um dos principais personagens na trama da crise brasileira. As evidências que sugerem o envolvimento de Temer com práticas de corrupção são robustas e de amplo conhecimento da sociedade brasileira, especialmente após a prisão de Rodrigo Rocha Loures, assessor direto do Presidente da República, que carregava uma mala cheia de dinheiro. Mesmo diante desse cenário, não vemos as mesmas manifestações populares que entre 2013 e 2016 desestabilizaram o governo de Dilma Rousseff.

Para ser ainda mais claro: mesmo com evidências contundentes do envolvimento de Michel Temer com todo tipo de corrupção, as ruas estão caladas, nada acontece. Parece, então, que a cultura política liberal conservadora, pautada na ética deontológica, hoje, no atual momento, perdeu a capacidade de inspirar as práticas políticas da sociedade civil, de levar às ruas os mesmos grupos que tanto apoiaram a destituição de Dilma Rousseff. Por que isso acontece? Por que o clamor popular por uma ética procedimental foi tão raivoso com Dilma Rousseff e está sendo tão manso com Michel Temer? Para esclarecer esses problemas seria necessário um estudo mais focado nos movimentos mais recentes da crise, o que não foi meu interesse aqui, neste artigo. Por isso, acredito que se este artigo tem alguma validade no esforço de compreensão da crise, essa validade está circunscrita ao período compreendido entre o início das “jornadas de 2013" e a destituição de Dilma Rousseff, quando o debate público brasileiro foi pautado por uma narrativa que, ao 
tratar o conceito corrupção na chave do liberalismo conservador, acabou por oferecer uma legitimação ética ao projeto neoliberal de desmonte do Estado.

Ainda é cedo para saber se essa narrativa de legitimação ética será o suficiente para garantir o apoio da sociedade brasileira à Reforma da Previdência, que é, na altura em que escrevo, a agenda reformista que mais encontra dificuldade de aprovação no Congresso Nacional, justamente pela enorme rejeição que a matéria encontra na opinião pública. Porém, com o que temos de experiência de crise até aqui, acredito ser possível afirmar que as forças políticas que sustentam esse projeto neoliberal estão convencidas de que o investimento na narrativa liberal-conservadora e na sua leitura do fenômeno da corrupção é o caminho a ser trilhado na disputa pelo imaginário da sociedade. Afinal, não é de hoje que os brasileiros e as brasileiras estão às voltas com a tal corrupção.

\section{THE MEANING OF THE “CORRUPTION” CONCEPT IN THE POLITICAL SEMANTIC OF THE BRAZILIAN CRISIS (2013-2016)}

Abstract: In the last years, the Brazilian political system was shaken by a crisis that that surpassed the limits of the institutions of the Republic and came to the streets. This crisis can be studied in different ways, which is being done by specialized studies. Here, in this article, I analyze a specific moment in the evolution of the crisis: the period between the "jornadas de junho de 2013" and the deposition of President Dilma Rousseff, with the aim to understanding the semantic dimension of crisis, the narratives that materializing in political practices, that inspired various sectors of Brazilian society to represent the reality in a certain perspective. My hypothesis, therefore, is that between 2013 and 2016, the semantics of the Brazilian crisis was based on the hypertrophy of a specific meaning of the concept of "corruption" and, consequently, a way of addressing the problem of "ethics in politics" which translate values belonging to the conceptual repertoire of conservative liberalism which had been circulating in the Brazilian political scene since the 1990s.

Keywords: Brazilian Crisis. Conservative Liberalism. Corruption. Political Semantics. Political Practices. 
O significado do conceito "corrupção" na semântica política...

\section{Notas}

${ }^{1}$ Ver os estudos de Marco Nobre (2013), Pablo Ortellado (2013) e de Vitor Cei e David Borges (2015).

${ }^{2}$ Entre as mais importantes pesquisas estatísticas realizadas nos primeiros momentos das "Jornadas de 2013" destacam-se os dois levantamentos feitos pelo Datafolha em São Paulo, nos dias 17 e 20 de junho; a pesquisa realizada na manifestação do Rio de Janeiro no dia 20 de junho pela Plus Marketing; a pesquisa nacional realizada pelo Ibope nas manifestações do dia 20, com 2002 entrevistas em oito cidades: São Paulo, Rio de Janeiro, Belo Horizonte, Porto Alegre, Recife, Fortaleza, Salvador e Brasília. Esses dados foram tabulados por André Singer no artigo "Brasil, junho de 2013: classes e ideologias cruzadas", que está devidamente referenciado no final deste ensaio.

\section{Referências}

ACERVO. Revista Veja, São Paulo, jun. 2013. Disponível em: <https://acervo. veja.abril.com.br/\#/edition/2328?page $=20 \&$ section $=1 \&$ word $=$ Maycon $\% 20 \mathrm{de} \%$ 20Freitas>. Acesso em: 4 mar. 2017.

ARCARY, Valério. Acabou o amor: a ruína do lulismo e os dilemas da oposição de esquerda. In: DEMIER, Felipe; HOEVELER, Rejane (Org.). A onda conservadora: ensaios sobre os atuais tempos sombrios no Brasil. Rio de Janeiro: Ed. Mauad, 2016. p. 107-118.

BENEVIDES, Maria Victoria de Mesquita. A UDN e o udenismo: as ambiguidades do liberalismo brasileiro. São Paulo: Paz e Terra, 1996.

BERSTEIN, Serge. Culturas políticas e historiografia. In: AZEVEDO, Cecília; ROLLEMBERG, Denise. Cultura política, memória e historiografia. Rio de Janeiro: Ed. FGV, 2009. p. 29-47.

BOM DIA BRASIL. Polícia Militar utiliza violência para reprimir protesto em São Paulo. Revista Veja, São Paulo, 14 jun. 2013. Disponível em: <http://g1.globo.com/ bom-dia-brasil/noticia/2013/06/policia-militar-utiliza-violencia-para-reprimirprotesto-em-sao-paulo.html>. Acesso em: 20 abr. 2017.

BRAGA, Ruy. Terra em Transe: o fim do lulismo e o retorno da luta de classes. In: LOUREIRO, Isabel; SINGER, André (Org.). As contradições do lulismo. São Paulo: Boitempo, 2016. p. 55-92.

. Sob a sombra do precariado. In: MARICATE, Ermínia (Org.). Cidades rebeldes. São Paulo: Boitempo, 2013.

Anos 90, Porto Alegre, v. 25, n. 48, p. 379-408, dez. 2018 
CARDOSO, Fernando Henrique. Social democracia hoje. Folha de São Paulo, São Paulo, 25 jul. 1990.

. Mensagem ao Congresso Nacional. Brasília, DF: fev. 1995. Disponível em: <http://biblioteca.presidencia.gov.br/presidencia/ex-presidentes/fernandohenrique-cardoso/mensagens-ao-congresso/1995/@@download/file/FHC\%20\%20Mensagem\%20ao\%20Congresso\%20Nacional\%201995.pdf>.

DARDOT, Pierre; LAVAL, Christian. A nova razão do mundo: ensaio sobre a sociedade neoliberal. São Paulo: Boitempo, 2016.

DEMIER, Felipe. Depois do golpe: a dialética da democracia blindada no Brasil. Rio de Janeiro: Mauad X, 2017.

FOLHA de São Paulo. São Paulo, abr., maio e jun. 1994.

GUERRA, Roberto Rodrigues. El liberalismo conservador contemporâneo. Santa Cruz de Tenertie: Universidade de La Laguna, 1998.

HAYEK, Friedrich. O caminho para a servidão. Rio de Janeiro: Edições 70, 2009. JAGUARUBE, Helio. Social Democracia Hoje. Folha de São Paulo, São Paulo, 23 jul. 1990.

JORNAL NACIONAL. SP: protesto contra aumento de passagens causa nova confusão. Revista Veja, São Paulo, 7 jun. 2013. Disponível em: <http://g1.globo. com/jornal-nacional/noticia/2013/06/sp-protesto-contra-aumento-de-passagenscausa-nova-confusao.html>. Acesso em: 20 abr. 2017.

KINZO, Maria D’Alva. Radiografia do quadro partidário brasileiro. São Paulo: Konrad-Adenauer-Stiftung, 1993.

LAMOUNIER, Bolívar. Partidos e utopias: o Brasil no limiar dos anos 90. São Paulo: Loyola, 1990.

MARX, Karl. Luta de classes em França. Ed. Boitempo: Rio de Janeiro, 2014. MASSOT, Xavier; VAN DEUSEN, David. The Black Bloc Papers: an anthology of primary texts from the North American Anarchist Black Bloc. Shawnee Mission: Alternative Media Project, 2010.

MATTOS, Marcelo Badaró. De junho de 2013 a junho de 2015: elementos para uma análise crítica da conjuntura brasileira. In: DEMIER, Felipe; HOEVELER, Rejane (Org.). A onda conservadora: ensaios sobre os atuais tempos sombrios no Brasil. Rio de Janeiro: Ed. Mauad, 2016. p. 93-106.

MELHEN, Célia Soiblemanm. Política de botinas amarelas: dinâmica eleitoral e organização partidária do MDB/PMDB paulista de 1965 a 1988. São Paulo: Hucitec, 1998. 
O significado do conceito "corrupção" na semântica política...

MOVIMENTO Passe Livre anuncia que não vai mais convocar protestos. $O$ Globo, São Paulo, 21 jun. 2013. Disponível em: 〈http://oglobo.globo.com/brasil/ movimento-passe-livre-anuncia-que-nao-vai-mais-convocar-protestos-8766919>. Acesso em: 20 abr. 2017.

NOBRE, Marco. Imobilismo em desenvolvimento: da abertura democrática ao governo Dilma. São Paulo: Companhia das Letras, 2013.

ORTELLADO, Pablo. Em 20 centavos: a luta contra o aumento. São Paulo: Veneta, 2013.

PEREIRA, Bresser. Social Democracia Hoje. Folha de São Paulo, São Paulo, 23 jul. 1990.

ROMA, Celso. A institucionalização do PSDB entre 1988 e 1999. RBCS, Viçosa, MG, v. 17, n. 49, jun. 2002.

SCHERER-WARREN, Ilse. Redes emancipatórias: nas lutas contra a exclusão e por direitos humanos. Curitiba: Editora Appris, 2012.

SINGER, André. A (falta de) base política para o ensaio desenvolvimentista. In: LOUREIRO, Isabel; SINGER, André (Org.). As contradições do lulismo. São Paulo: Boitempo, 2016. p. 21-54.

. Brasil, junho de 2013: classes e ideologias cruzadas. Novos Estudos, São Paulo, n. 97, nov. 2013.

SPENCER, Herbert. Essays: Scientific, Political and Speculative. v. III. Londres: Williams and Norgate, 1888.

SOUZA, Cláudio André. Antipetismo e ciclo de protestos no Brasil: uma análise das manifestações ocorridas em 2015. Em Debate, Belo Horizonte, v. 8, n. 3, p. 35-51, maio 2016.

SOUZA, Jessé. A radiografia do golpe. Rio de Janeiro: Leya, 2016. . A elite do atraso: da escravidão à lava jato. Rio de Janeiro: Leya, 2017. . A tolice da inteligência brasileira. Rio de Janeiro: Leya, 2018.

TRANFAGLIA, Nicola. Liberalismo (verbete). In: BOBBIO, Norberto. Dicionário de Política. Brasília, DF: Ed. UNB, 1995. p. 686-708.

VITA, Álvaro de. Liberalismo. In: AVRITZER, Leonardo et al. Corrupção: ensaios e críticas. Belo Horizonte: Ed. UFMG, 2012. p. 79-87.

Recebido em: 20/02/2018

Aprovado em: 30/07/2018

Anos 90, Porto Alegre, v. 25, n. 48, p. 379-408, dez. 2018 